\title{
Costs for in hospital treatment of urinary lithiasis in the Brazilian public health system
}

\author{
Custo do tratamento hospitalar da litíase urinária para o Sistema Único de Saúde brasileiro
}

\author{
Fernando Korkes ${ }^{1}$, Jarques Lúcio da Silva II $^{1}$, Ita Pfeferman Heilberg ${ }^{2}$
}

\begin{abstract}
Objective: To estimate costs associated to hospital treatment of urinary lithiasis in the Brazilian public health system as well as to evaluate demographic and epidemiological data referred to hospital admissions in the Brazilian public health system (or unified health care system). Methods: Data from the Informatic Department of Brazilian public health system were obtained as referred to costs in hospital admissions for urinary lithiasis during 2010 and also epidemiological data from 1996 through 2010. Results: There were 69,039 hospital admissions for urinary lithiasis, totaling $0.61 \%$ of all hospital admissions in the Brazilian public health system. The mean cost of each of these hospital admissions was US\$240,23 or $\mathrm{R} \$ 423.42$ having as result an overall cost of US $\$ 16,240,378.00$ or $\mathrm{R} \$ 29.232 .682,56$. Hospital admissions for urinary lithiasis in the Brazilian public health system increased 69\% from 1996 to 2010 $(43,176$ versus 69,$309 ; p<0.001 ; 0 R=1.69)$. The number of hospital admissions was $5 \%$ greater between December and March as compared to the period between June and September $(35,290$ versus 33,749; $\mathrm{p}<0.001$; $\mathrm{OR}=1.10$ ). For Caucasian patients the hospital admission was $75 \%$ greater as compared to black patients (63.2\% versus $35.8 \% ; p=0.02 ; \mathrm{OR}=1,75)$. Conclusion: Hospital admission for urinary liyhiasis has an elevated impact on the public health system with a cost of US\$16,2 or R $\$ 29.2$ million per year. The number of hospital admissions was greater in hotter months than in cold ones and also in the last decade, mainly in Caucasian population. These data may be helpful for the organization and optimization of health programs in the public health system as referred to prevention and treatment of urinary lithiasis in Brazil.
\end{abstract}

Keywords: Epidemiology; Urinary calculi/economics; Nephrolithiasis; Costs and cost analysis; Brazil

\section{RESUMO}

Objetivo: Estimar os custos associados ao tratamento hospitalar da litíase urinária no sistema público de saúde brasileiro, bem como avaliar dados demográficos e epidemiológicos referentes às internações por litíase urinária no Sistema Único de Saúde no Brasil. Métodos: Foram avaliados dados do Departamento de Informática do Sistema Único de Saúde referentes aos custos de internações hospitalares por diagnóstico de litíase urinária durante 2010 e dados epidemiológicos do período compreendido entre 1996 e 2010. Resultados: Durante 2010, houve 69.039 admissões hospitalares devido à litíase urinária, totalizando 0,61\% das internações hospitalares do Sistema Único de Saúde. 0 custo médio destas internações foi $R \$ 423,42$, culminando no gasto de $R \$ 29.232 .682,56$. Houve aumento de $69 \%$ no volume de internações por litíase no Sistema Único de Saúde entre 1996 e 2010 (43.176 versus 69.309; $p<0,001$; $O R=1,69$ ). 0 número de internações hospitalares foi $5 \%$ maior entre dezembro a março comparado ao período entre junho e setembro (35.290 versus 33.749 ; $p<0,001 ; O R=1,10)$. 0 percentual de internação por litíase urinária em indivíduos brancos foi $75 \%$ maior do que entre os negros $(63,2$ versus 35,8\%; $p=0,02 ; 0 R=1,75)$. Conclusão: As internações por litíase urinária determinam elevado impacto na Saúde Pública, com gasto de $\mathrm{R} \$ 29,2$ milhões/ano. 0 número de internações devido à doença litiásica é maior nos meses quentes em relação aos mais frios e tais internações têm ocorrido com frequência muito maior na última década, especialmente na população de etnia branca. Essas informações podem auxiliar na estruturação e na otimização de programas de saúde pública voltados à prevenção e ao tratamento da litíase urinária no Brasil.

Descritores: Epidemiologia; Cálculos urinários/economia; Nefrolitíase; Custos e análise de custo; Brasil

\section{INTRODUCTION}

Epidemiological data on urinary lithiasis in Brazil are scarce and there are no precise population-based studies on its incidence or prevalence. However, urolithiasis is a highly frequent disorder that affects about $11 \%$ of the general population at some time of their lives ${ }^{(1)}$. In a

\footnotetext{
Study carried out at Faculdade de Medicina do ABC - FMABC, Santo Andre (SP), Brazil; Universidade Federal de São Paulo - UNIFESP, São Paulo (SP), Brazil.

1 Faculdade de Medicina do ABC - FMABC, São Paulo (SP), Brazil.

2 Universidade Federal de São Paulo - UNIFESP, São Paulo (SP), Brazil.

Corresponding author: Fernando Korkes - Rua Pirapora, 167 - Ibirapuera - CEP 04008-060 - São Paulo (SP), Brazil - Tel.: 5511 3884-2233 - E-mail: fkorkes@terra.com.br

Received on: Jun 15, 2011 - Accepted on: Oct 25, 2011

Conflict of interest: none
} 
country with continental dimensions, and a population of 185.7 million inhabitants ${ }^{(2)}$, a high economic impact is expected associated with diagnosis, treatment, and absenteeism because of urinary lithiasis, especially since it is more common in adults, at working age. Nevertheless, as far as we know, there are no studies to evaluate the costs associated with lithiasis in Brazil.

\section{OBJECTIVE}

To evaluate the costs associated with the hospital treatment of urinary lithiasis in the Brazilian public health system. As secondary objectives, we also observe epidemiological tendencies associated with hospital admission due to urinary lithiasis in the Brazilian public health system.

\section{METHODS}

Data from the Brazilian public health system or Unified Healthcare System (SUS) were analyzed, obtained by means of the Information Technology Department of the SUS (DATASUS) ${ }^{(3)}$. Epidemiological data from 1996 to 2010 were evaluated, as well as data on costs during the year 2010, seeking patients admitted with a primary diagnosis of urinary lithiasis as per the International Classification of Diseases (ICD) N20.-, N21.-, N23.- (calculus of kidney and ureter, calculus of lower urinary tract, and renal colic). As a population base for comparison, data from the last national census performed by the Brazilian Institute of Geography and Statistics (IBGE), in 2010 (2), were used.

Statistical analyses were carried out utilizing the Statistical Package for the Social Sciences (SPSS) 13 software, for Mac OS X, and Fisher's test for nonparametric variables, adopting statistical significance of $\mathrm{p}<0.05$.

\section{RESULTS}

According to the IBGE data, the Brazilian population in 2010, was $185,712,713$ inhabitants ${ }^{(2)}$. Of this total, about $70 \%$ received health care exclusively through the SUS, corresponding to approximately 130 million Brazilians $^{(2)}$.

According to DATASUS, there were 69,039 hospital admissions directly related to urinary lithiasis during $2010^{(3)}$. These numbers corresponded to $0.61 \%$ of hospitalizations at the SUS during 2010. The average costs of these hospital stays was $\mathrm{R} \$ 423,42$, adding to a total expense of $\mathrm{R} \$ 29,232,682.56$.

In evaluating the number of hospitalizations due to urolithiasis, an increase from 43,176 to 69,309 admissions was observed between 1996 and 2010

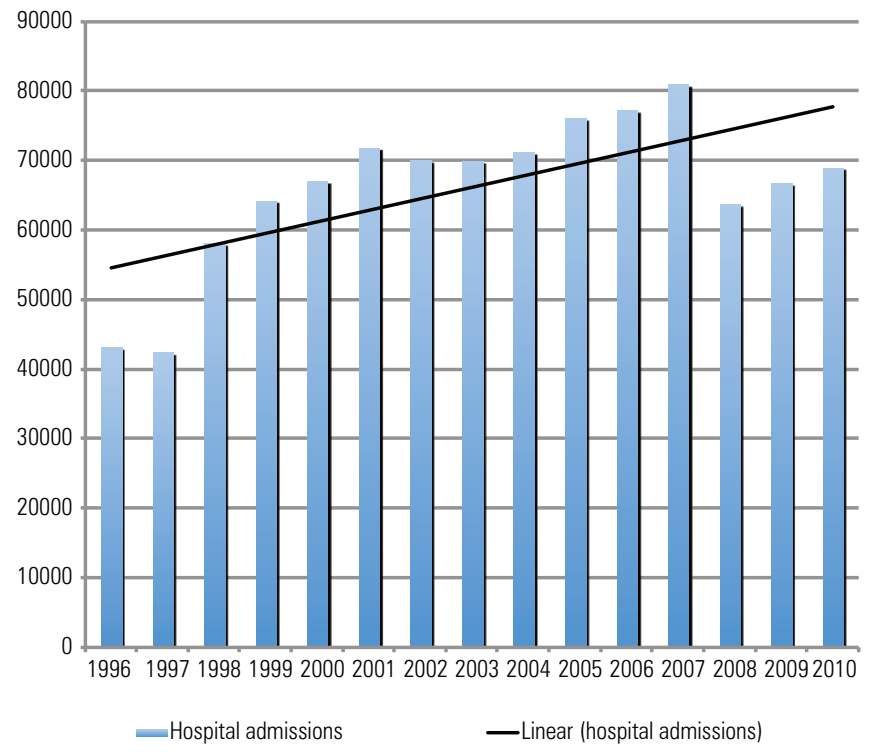

Figure 1. Distribution of hospital admissions due to diagnosis of urinary lithiasis in Brazil according to data from the Unified Health System, 1996 to $2010^{(3)}$

(Figure 1), whereas during this same period there was a reduction in the total number of hospitalizations by the SUS $(11,932,654$ versus 11,347,729). Thus, proportionately, there was a $69 \%$ increase in the number of hospital admissions for urinary lithiasis, that went from $0.36 \%$ in 1996 to $0.61 \%$ in 2010 (p < 0.001, OR $=1.69$ ), considering all hospitalizations through the SUS. During 2010, it was also noted that the number of hospital admissions was 5\% higher during the warmer months (December to March) in comparison to the cooler period (June to September) of the year $(35,290$ versus $33,749, \mathrm{p}<0.001, \mathrm{OR}=1.1)$.

Table 1 shows hospital stays according to the distinct geographical regions of the country. The total number of admissions in the regions South, Southeastern, and Center West were proportionately greater than those of the regions North and Northeast, even when corrected by population density $(\mathrm{p}<0.005$; OR $=1.7)$.

Table 1. Distribution of hospital admissions at the Unified Health System due to diagnosis of urinary lithiasis according to different Brazilian geographic regions, as compared to the total population of each region, during $2010^{(2,3)}$

\begin{tabular}{lcccc}
\hline Region & $\begin{array}{c}\text { Hospital admissions due to } \\
\text { urinary lithiasis }\end{array}$ & \multicolumn{2}{c}{$\begin{array}{c}\text { Total } \\
\text { population }^{(2)}\end{array}$} \\
\cline { 2 - 5 } & $\mathbf{n}$ & $\%$ & Millions & $\%$ \\
\hline North & 3707 & 5.37 & 15.80 & 8.28 \\
Northeast & 13590 & 19.68 & 53.07 & 27.82 \\
Center West & 8655 & 12.54 & 14.26 & 7.48 \\
Southeast & 31266 & 45.29 & 80.30 & 42.10 \\
South & 11821 & 17.21 & 27.30 & 14.31 \\
\hline Total & 69039 & 100 & 190.73 & 100 \\
\hline
\end{tabular}

As to distribution by gender, an equivalence among hospital admissions due to urolithiasis was noted 
between men and women (49.9 versus $50.1 \%$; $\mathrm{p}=0.60)$, a result that has been stable since 1998, when this piece of information became available.

The distribution as per age groups is shown in Figure 2. Of the total number of patients hospitalized in 2010, 62.2\% were aged between 20 and 49 years. As to ethnicity, $63.2 \%$ were white, $35.8 \%$ black, $0.7 \%$ Asian, and $0.2 \%$ Indian. A proportional risk $79 \%$ greater was observed in hospitalization for urinary lithiasis for white individuals $(63.2 \%$ white versus $35.8 \%$ black; $p<$ 0.0001 ; OR $=1.79$ ) when weighted for the due Brazilian population proportions, and $75 \%$ greater when weighted for the total proportion of hospitalizations through the SUS during $2010(\mathrm{p}=0.02$; OR $=1.75)$.

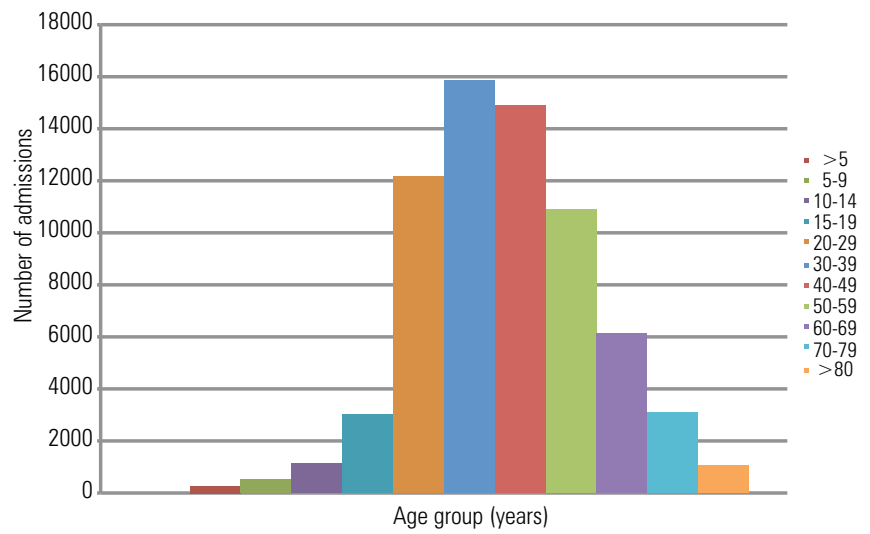

Figure 2. Distribution of hospital admissions at the Unified Health System per age group, Brazil, 2010

In 2010, hospital admissions were directly responsible for 236,402 days of absenteeism at work; the average period of hospital stay was 3.4 days and there were 201 deaths among patients admitted for urolithiasis (mortality rate of $0.29 \%$ ). The cost expended with the treatment of these inpatients was R \$ 29.2 million in 2010.

\section{DISCUSSION}

\section{Financial impact of lithiasis in Brazil}

Lithiasic disease represents an expressive proportion of the budget for health due to its high prevalence and recurrence in the population ${ }^{(4)}$. During the year 2010, hospital admissions due to urolithiasis were responsible for $0.61 \%$ of the total number of hospitalizations of the Brazilian population seen by the SUS. These numbers become even more impressive if we consider that most individuals with urinary calculi are treated as outpatients, and not as inpatients. Therefore, these data also do not take into consideration the costs resulting from outpatient visits, laboratory tests, imaging tests, and medications used to treat these patients. In this way, it is estimated that lithiasic disease represents a high economic impact on national public health.

Additionally, more than $60 \%$ of the total numbers of patients from the Brazilian population hospitalized in 2010 were aged between 20 and 49 years, which means, in age groups of greatest professional productivity. A study in our midst that evaluated outpatients with urinary lithiasis observed that the mean age of occurrence of the first symptoms was 36.9 years ${ }^{(5)}$. Similarly, in a large multicenter study involving 1320 patients with lithiasis coming from 8 different states in Brazil (Bahia, Parana, Pernambuco, Rio Grande do Sul, Alagoas, Rio de Janeiro, Minas Gerais, and Sao Paulo) revealed that the average age was $42 \pm 13$ years $^{(6)}$.

Besides the high rates of absenteeism at work during 2010 (236,402 days), if we consider the days of home rest these patients were submitted to after hospital discharge, and the number of deaths during these hospital stays $(\mathrm{n}=201)$, the social and economic impact is very significant.

Although we do not have data related to the extrahospital treatment of patients with urinary lithiasis, if we consider the intra-hospital costs of $\mathrm{R} \$ 29.2$ million/ year during 2010, we can estimate values based on NorthAmerican studies ${ }^{(7)}$. Applying the same proportions of expenses found there, one can speculate on a cost of approximately $\mathrm{R} \$ 18.2$ million/year with outpatient treatment, $\mathrm{R} \$ 14.7$ million/year with emergency treatments, representing a total of $\mathrm{R} \$ 62.1$ millions/year spent directly on the treatment of uriolithiasis by the SUS.

The SUS covers 64 thousand accredited facilities, and carries out about 2.3 billion outpatient procedures a year (254 million in clinical visits and 11.3 million in hospitalizations). Costs with the SUS amount to $3.4 \%$ of the national gross domestic product (GCP), representing a budget of $\mathrm{R} \$ 40$ billion/year. Hence it is estimated that treatment for urinary lithiasis consumed $0.22 \%$ of all expenses of the Brazilian public health system during 2010. According to a previous study carried out in the city of Ribeirao Preto (SP) $)^{(5)}$, hospitalization due to diagnosis of urolithiasis consumed $3.37 \%$ of the total value spent with hospital admissions - a number even more expressive than that found in the present study, at national level. These data highlight the importance of having well-structured and effective public health measures in order to allow optimization of treatment and, possibly, a reduction in costs associated with urinary lithiasis.

\section{Epidemiologic tendencies associated with urinary lithiasis}

When evaluating the number of hospitalizations through the SUS from 1996 to 2010, there was a 
significant increase, which opposes the data of other authors outside the country who observed a tendency towards stability, or a slight increase in the number of hospitalizations in large epidemiological studies $^{(8,9)}$. While Mandel et al. ${ }^{(8)}$ demonstrated constant rates of hospitalization over the last decade in the United States in the group of war veterans ${ }^{(8)}$, Pearle et al. ${ }^{(10)}$ identified a $15 \%$ decrease in the number of admissions due to lithiasis between 1994 and 2000 in that country ${ }^{(10)}$. Our findings may be attributed to an increase in the incidence of urolithiasis, according to what has been suggested by several authors ${ }^{(11)}$, but one cannot exclude the possibility that such findings simply reflect other factors, such as improvement in epidemiological data collection and in access of the population to the SUS services, or, yet, improved diagnostic methods for renal lithiasis, for example, by means of imaging tests, as has already been observed by other investigators ${ }^{(12)}$.

According to IBGE data, the Brazilian population is represented by $49.7 \%$ o white and $49.5 \%$ of black individuals ${ }^{(2)}$. In evaluating the total number of hospitalizations through the SUS during 2010, these proportions are maintained $(49.7 \%$ white versus $49.1 \%$ black). And assessing hospitalization due to urinary lithiasis as per ethnic group, a 75 to $79 \%$ higher risk of hospital admission was observed due to this condition for Caucasians. These data suggest that, similar to what is seen in other countries ${ }^{(11)}$, there is also in Brazil a tendency of white individuals presenting with a higher prevalence of lithiasic diseases than black individuals.

\section{Environmental and climatic factors}

Similar to what was previously demonstrated in the United States ${ }^{(13)}$ and in other regions of the world ${ }^{(4)}$, where a great geographic variability of lithiasic disease is observed ${ }^{(4)}$, it is speculated that the same occurs in Brazil. In smaller magnitude national studies ${ }^{(6)}$, a great variation was noted among the distinct regions of Brazil in terms of frequency of lithiasis. This occurs because of the different climate conditions, dietary habits, occupations, and metabolic disorders ${ }^{(6,13)}$.

Hospital admissions due to lithiasis are known to oscillate according to climate variations ${ }^{(13)}$. In Brazil, there are two clearly delimited climate seasons. During the period evaluated, there was a 5\% increase in hospital admissions during the warmer months of the year. However, in evaluating hospitalizations in the distinct regions of the country during 2010, a distinctive preponderance was seen in the regions South, Southeast, and Center West, the areas with a cooler climate throughout the year. Nonetheless, these areas also correspond to the regions of greatest socioeconomic development, and therefore, are better equipped with hospital centers and have greater access of the population to medical services, which may explain such differences. Additionally, it is known that the migration of individuals from other more needy regions to undergo health treatments in the more developed regions should also contribute towards elevating the figures of the latter regions. The association of these observations could and should help establish public policies of prevention and optimization of treatment of urinary lithiasis. White individuals, and primarily during the summer months, characterize the population with the greatest risk of hospitalization due to lithiasic disease.

We cannot, however, omit reporting on some limitations of the present study. The data made available by the DATASUS were obtained based on the primary ICD reported at admission. In order to allow an adequate analysis, all codes related to urinary lithiasis (N20.-, N21.-, N23.-) were included, but the distinction among these was not made, as it would cause imprecisions. Moreover, hospitalizations due to other causes, but that resulted in a need for surgical interventions for urinary lithiasis, were not included in the data obtained. Still, the magnitude of the data and the scarcity of prior data make these limitations poorly representative.

\section{CONCLUSION}

Hospital admissions due to urinary lithiasis determine a great impact on public health, with a total cost of US\$ 16,2 million/year or $\mathrm{R} \$ 29.2$ million/year. The number of hospitalizations due to lithiasic disease was greater during the warm months, and these admissions occurred more frequently during the last decade, especially in the white population. All this information is extremely useful and may help to structure and optimize public health programs targeted at prevention and treatment of urinary lithiasis in Brazil.

\section{REFERENCES}

1. Worcester EM, Coe FL. Clinical practice. Calcium kidney stones. N Engl J Med. 2011;363(10):954-63.

2. Instituto Brasileiro de Geografia e Estatística (IBGE). Ministério do Planejamento, Orçamento e Gestão. Governo Federal do Brasil [Internet]. 2010 [citado 2011 Nov 1].Disponível em: http://www1.ibge.gov.br/home

3. Departamento de Informática do SUS (DATASUS) [Internet]. Brasília, DF: Ministério da Saúde, 2011 [citado 2011 Nov 1]. Disponível em: http://www2. datasus.gov.br/DATASUS/index.php

4. Pak CY, Resnick MI, Preminger GM. Ethnic and geographic diversity of stone disease. Urology. 1997;50(4):504-7.

5. Vannucchi MTI, Geleilete TJM, Bessa EL. Urolithiasis in public health services - aprevention protocol for outpatients. J Bras Nefrol. 2003;25(4):165-71.

6. Heilberg IP, Teixeira SH, Novoa CG, Barros E, Ferreira-Filho SR, Melo MEA, et al. The Brazilian multicentric study of nephrolithiasis (MULTILIT). In: Pak CYC, Resnick MI, Preminger GM, editors. Urolithiasis 1996. Proceedings of the 8th 
International Symposium on Urolithiasis. Dallas, TX: Millet the printer, Inc.; 1996. p. 498-9.

7. Lotan Y. Economics and cost of care of stone disease. Adv Chronic Kidney Dis. 2009;16(1):5-10.

8. Mandel NS, Mandel GS. Urinary tract stone disease in the United States veteran population. I. Geographical frequency of occurrence. J Urol. 1989;142(6):1513-5.

9. Stamatelou KK, Francis ME, Jones CA, Nyberg LM, Curhan GC. Time trends in reported prevalence of kidney stones in the United States: 1976-1994. Kidney Int. 2003;63(5):1817-23.
10. Pearle MS, Calhoun EA, Curhan GC. Urologic diseases in America project: urolithiasis. J Urol. 2005;173(3):848-57.

11. Curhan GC. Epidemiology of stone disease. Urol Clin North Am. 2007; 34(3):287-93.

12. Bansal AD, Hui J, Goldfarb DS. Asymptomatic nephrolithiasis detected by ultrasound. Clin J Am Soc Nephrol. 2009;4(3):680-4.

13. Soucie JM, Coates RJ, McClellan W, Austin H, Thun M. Relation between geographic variability in kidney stones prevalence and risk factors for stones. Am J Epidemiol. 1996;143(5):487-95. 